九州大学学術情報リポジトリ

Kyushu University Institutional Repository

\title{
Correlation of Physical Parameters with Steady- State Hardness of Pure Metals Processed by High-Pressure Torsion
}

Edalati, Kaveh

Department of Materials Science and Engineering, Faculty of Engineering, Kyushu University

Horita, Zenj i

Department of Materials Science and Engineering, Faculty of Engineering, Kyushu University

http://hdl. handle. net/2324/26387

出版情報: Materials Science Forum. 667-669, pp.683-688, 2010-12. Trans Tech Publications バージョン:

権利関係: (C) (2010) Trans Tech Publications, Switzerland 


\title{
Correlation of Physical Parameters with Steady-State Hardness of Pure Metals Processed by High-Pressure Torsion
}

\author{
Kaveh Edalati ${ }^{a}$ and Zenji Horita ${ }^{b}$ \\ Department of Materials Science and Engineering, Faculty of Engineering, Kyushu University, \\ Fukuoka 819-0395, Japan \\ a kaveh.edalati@zaiko6.zaiko.kyushu-u.ac.jp, ${ }^{\text {b }}$ horita@zaiko.kyushu-u.ac.jp
}

Keywords: ultrafine grained microstructure; severe plastic deformation; hardness.

\begin{abstract}
Pure metals of 30 elements with various crystal structures (bcc, fcc, hcp, diamond cubic, complex cubic, primitive hexagonal and tetragonal) are processed by high-pressure torsion (HPT) and their mechanical properties are subsequently evaluated by Vickers microhardness measurements. For all metals, the hardness reaches steady states at large strains where the hardness remains unchanged with further straining. It is shown that the hardness values at the steady state are characteristics of each metal and are successfully expressed as a unique function of the homologous temperature, shear modulus and physical parameters of metals such as melting temperature, specific heat capacity and diffusion coefficient except for a few elements. The findings are well applicable to predict the ultimate steady-state hardness of metals attained by HPT processing through the correlation established in this study.
\end{abstract}

\section{Introduction}

High strength and ultrafine-grained microstructures are satisfactorily attained in bulk pure metals through the application of high-pressure torsion (HPT) [1-4]. Earlier reports showed that the hardness variation is represented by a unique function of the equivalent strain in $\mathrm{Fe} \mathrm{[5],} \mathrm{V}$ [6], Mo [6], $\mathrm{Al}$ [7-10], $\mathrm{Cu}$ [11], Ag [12], Au [12], Ni [12], Pt [12], Ti [13], Zr [14] and Hf [15]. For all these pure metals, the hardness reaches steady state levels at high strains where the hardness remains unchanged with further straining. It appears that for each metal the steady state level is characteristic of the metal irrespective of the pressure and of the initial state of materials before processing [12,16].

Little is understood to date regarding the correlations between the hardness at the steady state and the mechanical and physical parameters of pure metals after processing with HPT. It was shown that the hardness at the steady state after processing with HPT is determined by shear modulus compensated by homologous temperatures for pure metals [12]. Another paper reported that the hardness at the steady state after processing with HPT is well correlated with the atomic bond energy and related parameters [17].

In the present study, 30 high-purity elements are processed by HPT and the correlations between the hardness and the homologous temperature, shear modulus, melting temperature, specific heat capacity and activation energy for self-diffusion are investigated.

\section{Experimental Procedures}

Pure metals and semi-metals of 30 elements (Mg, Al, Si, Sc, Ti, V, Cr, Mn, Fe, Co, Ni, Cu, Zn, Ge, $\mathrm{Zr}, \mathrm{Nb}, \mathrm{Mo}, \mathrm{Pd}, \mathrm{Ag}, \mathrm{In}, \mathrm{Sn}, \mathrm{Te}, \mathrm{Nd}, \mathrm{Hf}, \mathrm{Ta}, \mathrm{W}, \mathrm{Re}, \mathrm{Pt}, \mathrm{Au}$ and $\mathrm{Pb}$ ) with different crystal structures were investigated in this study. The purity levels were higher than $99 \%$ for Ta and $\mathrm{W}$ and $99.9 \%$ or higher for the other elements. The as-received specimens were cut to discs with $10 \mathrm{~mm}$ diameters and $0.8 \mathrm{~mm}$ thickness using a wire-cutting electric discharge machine. HPT was carried out on the discs at room temperature using the facilities described earlier [14]. The disc samples were processed under a selected pressure in the range of $P=2-6$ GPa for $N=0.5-10$ revolutions with a rotation speed of $\omega=$ 0.2-1.0 rpm at a temperature in the range of $\mathrm{T}=298-573 \mathrm{~K}$. For $\mathrm{Ti}$ and $\mathrm{Zr}$, the HPT was conducted 


\section{Materials Science Forum, Vols. 667-669 (2011), pp. 683-688}

under a pressure of $2 \mathrm{GPa}$, which is smaller than the critical pressure for $\omega$-phase formation $[13,14]$. The samples after HPT were kept at room temperature for $~ 30$ hours. Thereafter, the samples were polished to a mirror-like surface and the Vickers microhardness was measured from the center to edge at 8 different radial directions and the average values were then plotted against the equivalent strain. The hardness in this study was used from the steady state where the hardness remained unchanged with further straining.

\section{Results and Discussion}

Figure 1 plots the microhardness against equivalent strain for 7 selected metals ( $\mathrm{Al}, \mathrm{Ag}, \mathrm{Cu}, \mathrm{Pt}, \mathrm{Ni}, \mathrm{Fe}$ and Hf), demonstrating that all hardness data for each metal follow a unique function of equivalent strain. The hardness increases with increasing equivalent strain and then reaches a steady state at large strains except for Al. In high-purity $\mathrm{Al}$ (99.99\%), the hardness initially increases with increasing strain and, after reaching a maximum, decreases to a steady level. The mechanism for the unusual softening of pure $\mathrm{Al}$ at large strains was investigated in a few papers. Xu et al. [10] attributed the softening to easy cross-slip and dynamic recovery due to large stacking fault energy of Al. Edalati et al. [8] reported that a softening occurs in $\mathrm{Cu}$ at a homologous temperature of 0.32 in a similar way to Al because of a static recrystallization, and they attributed the softening in pure $\mathrm{Al}$ to its relatively high homologous temperature.

The microhardness at the steady state is plotted in Fig. 2 against the shear modulus, $G$, for elements processed by HPT at room temperature. In spite of some scatterings, the hardness values tend to increase linearly with an increase in $G$. Since the hardness at the steady state is directly proportional to $G$, it follows that $H V / G$ can be a constant which is $\sim 0.045 \pm 0.015$, except for $\mathrm{Si}, \mathrm{Ge}, \mathrm{Pb}, \mathrm{Sn}, \mathrm{Zn}$ and Al.

Microhardness values at the steady state are plotted in Fig. 3 against the melting temperature, $T_{m}$, for elements processed by HPT at room temperature. Figure 3 shows that the hardness tends to increase with an increase in $T_{m}$. However, scattering of the data points appears to be large around the fitted curve.

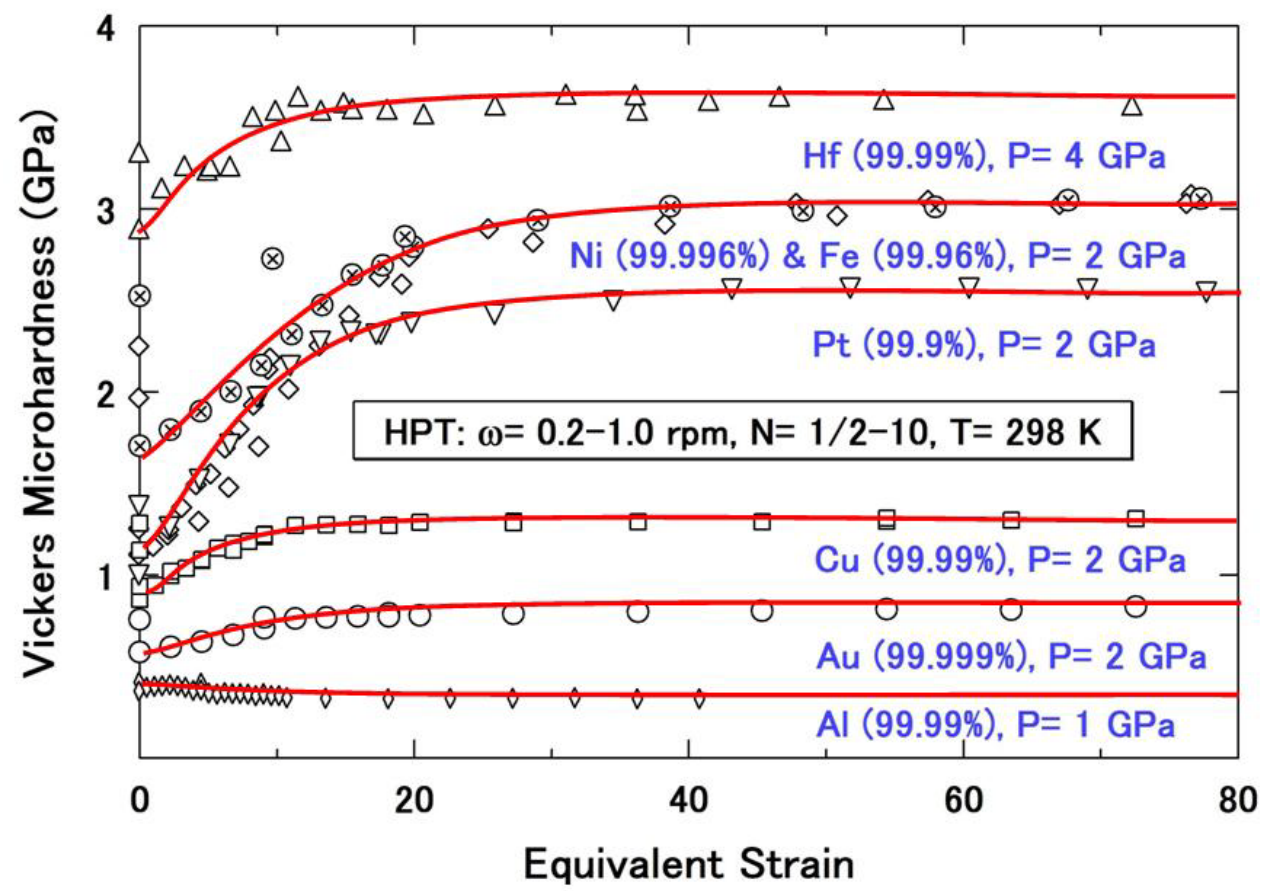

Fig. 1 Hardness plotted against equivalent strain for various metals. 


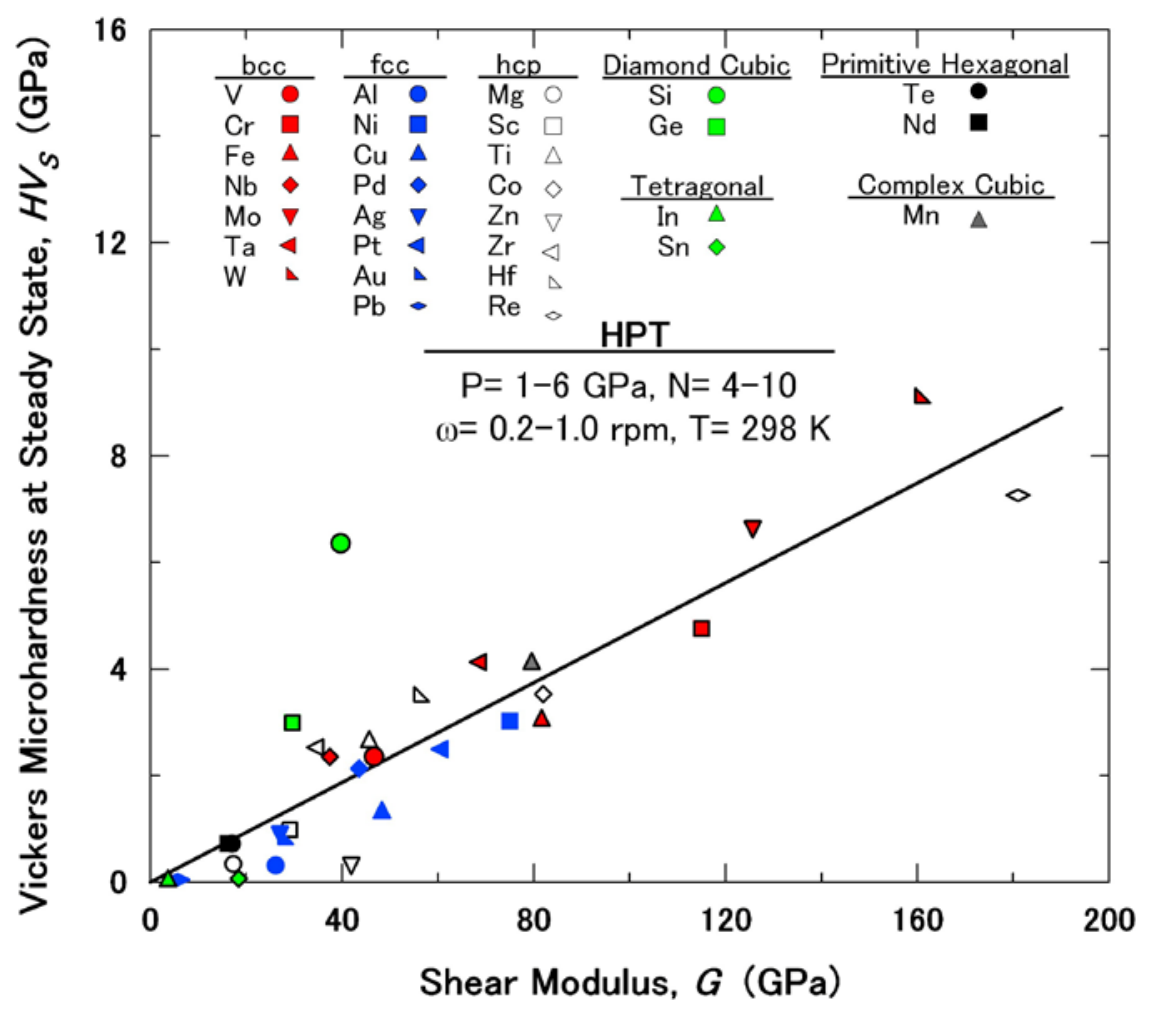

Fig. 2 Vickers microhardness at steady state plotted against shear modulus.

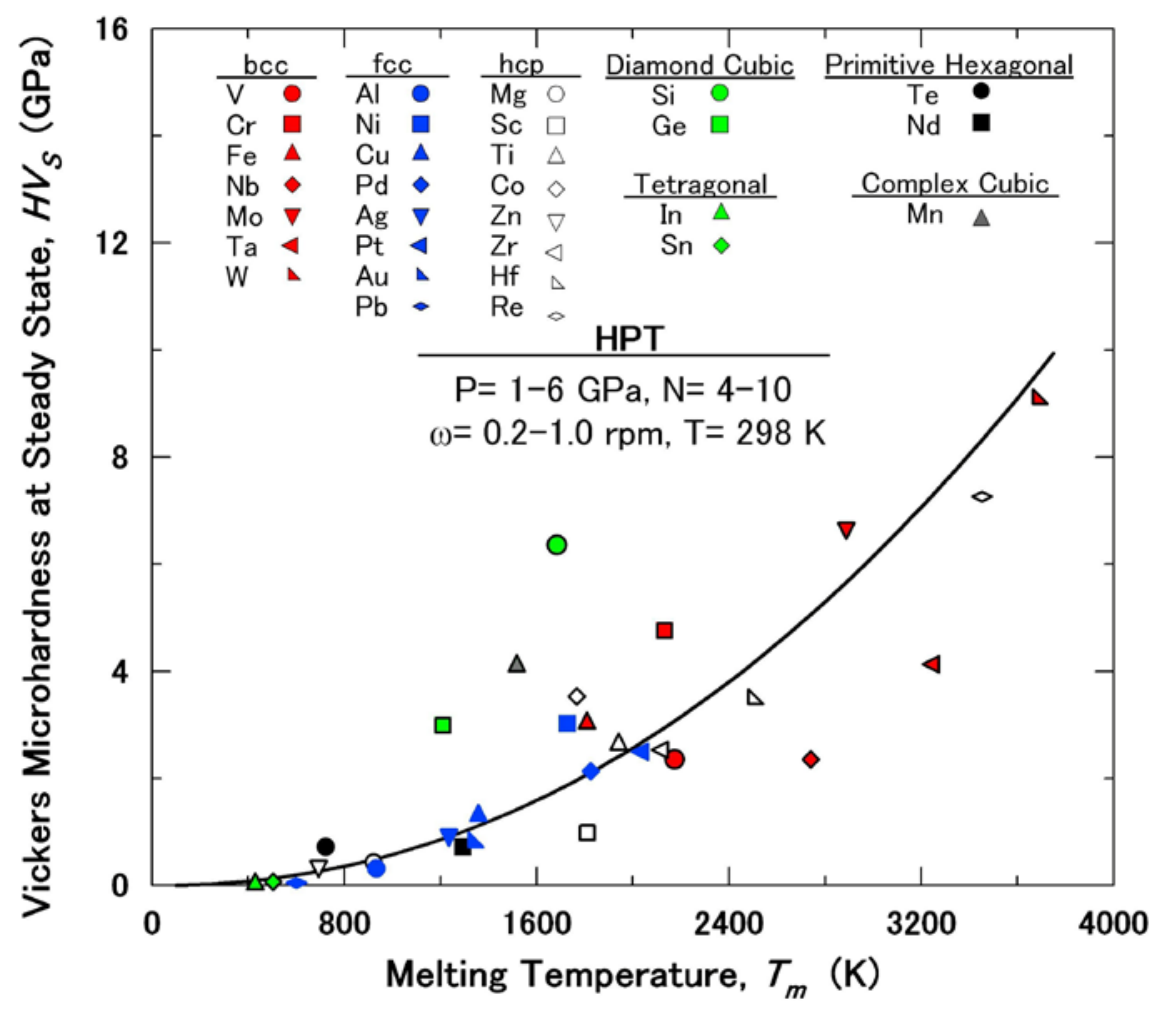

Fig. 3 Vickers microhardness at steady state plotted against melting temperature.

Frost and Ashby [19] found a good correlation between $H V / G$ and the homologous temperature, $T / T_{m}$, for single crystals of alkali halides. However, they reported no relationships between $H V / G$ and $T / T_{m}$ for pure metals. Suzuki et al. [20] plotted $H V / G$ versus $T / T_{m}$ for 5 polycrystalline $b c c$ metals and 
reported that $G$ and $T / T_{m}$ are not adequate scaling parameters. Because the mechanical properties of pure metals are influenced by the microstructural features such as the grain size, the dislocation density and the textures, and by the processing parameters such as the deformation technique and the imposed strain, it is not possible to establish a unique correlation between $H V, G$ and $T / T_{m}$ from the values at non-steady state conditions in Refs. $[19,20]$. The present authors found that $G$ and $T / T_{m}$ are important parameters to influence the hardness level at the steady state for pure metals subjected to HPT [12]. It is well known that $G$ is a parameter to explain dislocation interactions, deformation processes and hardening rate, and $T_{m}$ is a parameter to explain the activation energy for diffusion, recovery processes and softening rate. Since the hardness at the steady state attained by HPT is a consequence of a balance between hardening and softening processes, $G$ and $T / T_{m}$ must be important parameters to scale the hardness values at the steady sate.

The hardness values are normalized by $G$ and now plotted in Fig. 4 as a function of $T / T_{m}$. Inspection of Fig. 4 indicates most of the data points reasonably lie on a line except for some deviations from the line such as for $\mathrm{Si}$, Ge and Te of semi-metals, Ti, $\mathrm{Zr}$ and $\mathrm{Hf}$ in group IVB transition metals, and $\mathrm{Pb}$, In, $\mathrm{Sn}, \mathrm{Zn}$ and $\mathrm{Al}$ with low melting points.

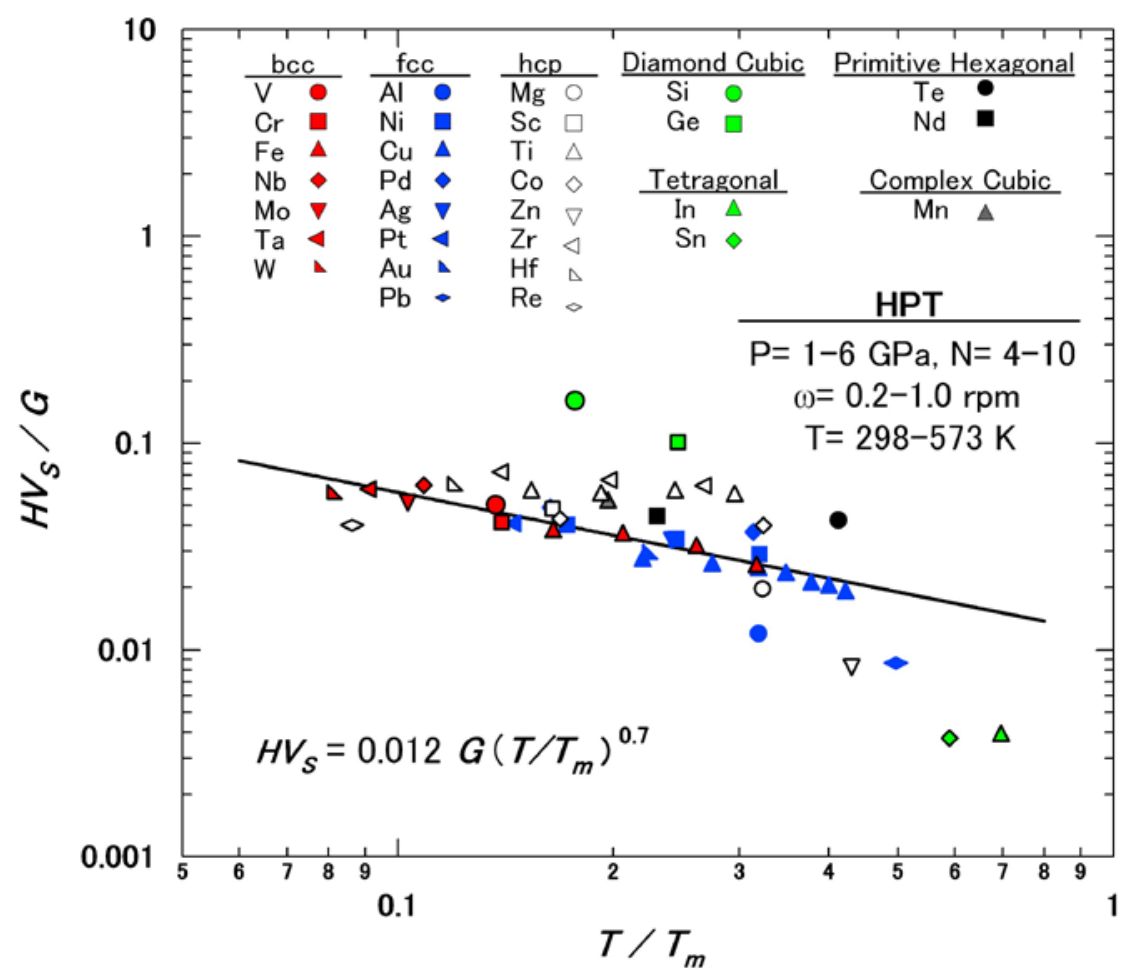

Fig. 4 Plot of $H V_{S} / G$ against $T / T_{\mathrm{m}}$ after processing by HPT. $H V_{S}$ : Vickers microhardness at steady state, $G$ : shear modulus, $T / T_{\mathrm{m}}$ : homologous temperature.

Figure 5 shows the variation of the hardness at the steady state with respect to $Q$. Here, $Q$ represents the maximum energy that can be stored in a unit volume before it melts [18]. It is apparent that the hardness values are well represented as a unique function of $Q$. The hardness increases monotonically with an increase in $Q$ except for $\mathrm{Si}$ and Ge having strong covalent bonds. Since the hardness increase with an increase in $Q$, the correlation indicates that the hardness level at the steady state depends upon the capability of energy storage in materials.

The hardness at the steady state is plotted in Fig. 6 against the activation energy for self-diffusion, $Q_{\mathrm{SD}}$. The hardness increases with an increase in $Q_{\mathrm{SD}}$ and all data points lie well on a single curve except for $\mathrm{Ti}, \mathrm{Zr}$ and $\mathrm{Hf}$ in group IVB and $\mathrm{Nb}$ in group VB. The correlation shown in Fig. 6 can be attributed to the fact that the thermal recovery, which is a crucial factor to reach a steady state, is related to $Q_{\mathrm{SD}}$ : the higher the $Q_{\mathrm{sD}}$, the smaller the recovery and thus the more enhanced the hardness. It is noted that Ti, 


\section{Materials Science Forum, Vols. 667-669 (2011), pp. 683-688}

$\mathrm{Zr}$ and Hf were also exception to the universal level determined by shear modulus compensated by homologous temperatures because of the reason as described in an earlier paper [12].

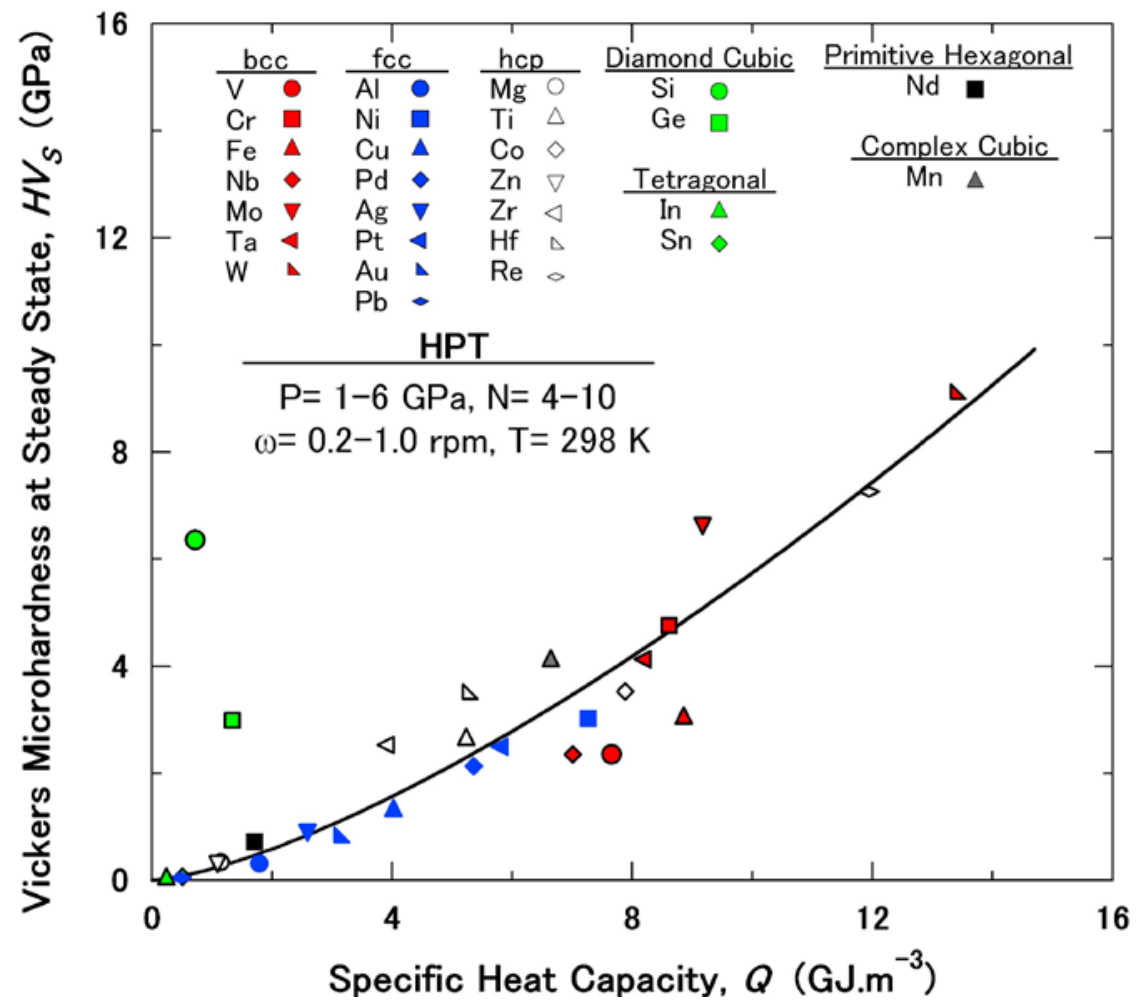

Fig. 5 Vickers microhardness at steady state plotted against specific heat capacity.

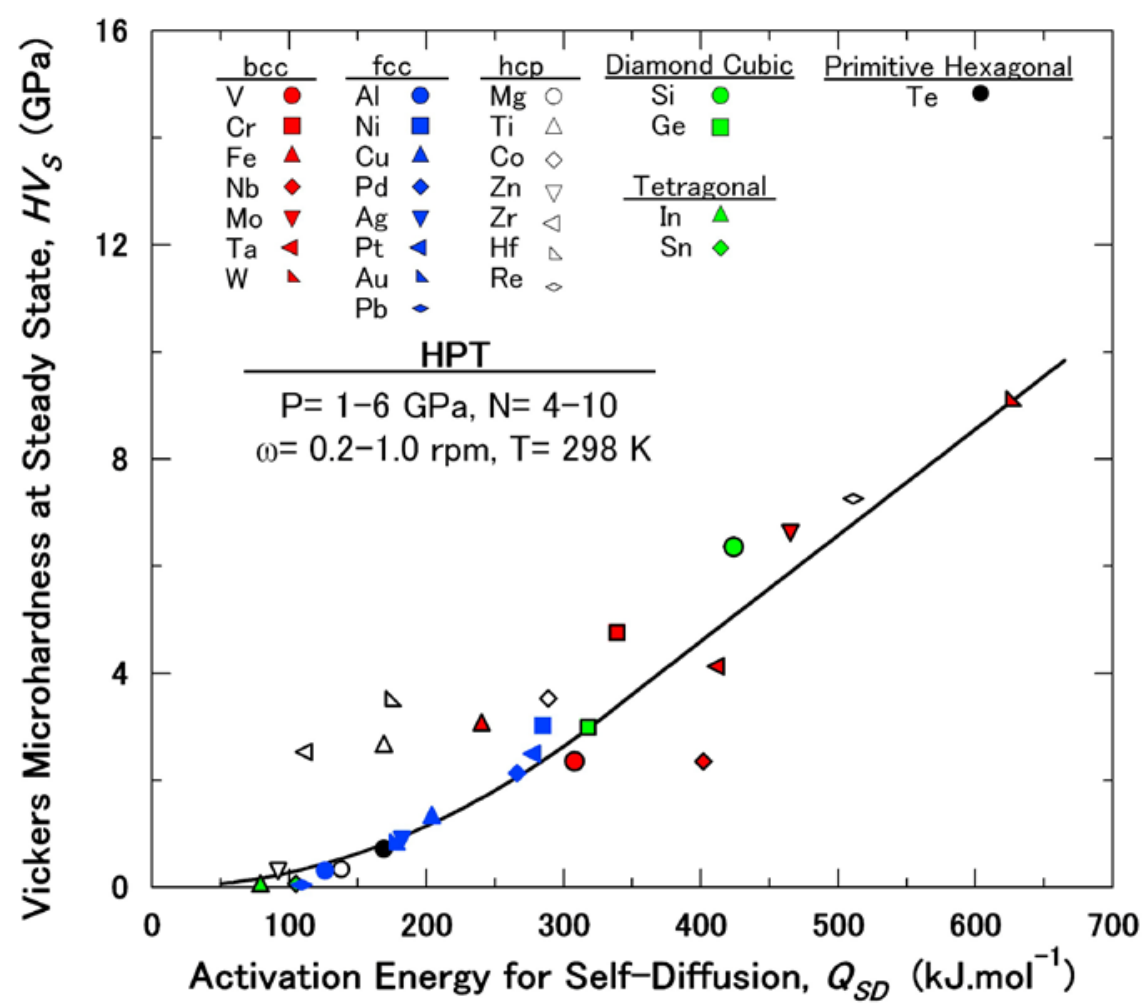

Fig. 6 Vickers microhardness at steady state plotted against activation energy for self-diffusion. 


\section{Materials Science Forum, Vols. 667-669 (2011), pp. 683-688}

\section{Conclusions}

Metals and semi-metals of 30 elements, with different crystal structures (bcc, fcc, $h c p$, diamond cubic, complex cubic, primitive hexagonal and tetragonal) were processed by high-pressure torsion and subsequently evaluated by Vickers microhardness measurements. The hardness at the steady state after processing with HPT are well documented through unique correlations with physical parameters such as the homologous temperature, shear modulus, melting temperature, specific heat capacity and the activation energy for self-diffusion.

\section{Acknowledgement}

One of the authors (KE) would like to thank the Islamic Development Bank (IDB) for a PhD scholarship and the Japan Society for promotion of Science (JSPS) for a postdoctoral scholarship. This work was supported in part by the Light Metals Educational Foundation of Japan, in part by a Grant-in-Aid for Scientific Research from the MEXT, Japan, in Innovative Areas "Bulk Nanostructured Metals" and in part by Kyushu University Interdisciplinary Programs in Education and Projects in Research Development (P\&P).

\section{References}

[1] P.W. Bridgman: Phys. Rev. Vol. 48 (1935), p. 847.

[2] R.Z. Valiev, R.K. Islamgaliev and I.V. Alexandrov: Prog. Mater. Sci. Vol. 45 (2000), p. 103.

[3] R.Z. Valiev, Y. Estrin, Z. Horita, T.G. Langdon, M.J. Zehetbauer and Y.T. Zhu: JOM Vol. 58(4) (2006), p. 33.

[4] A.P. Zhilyaev and T.G. Langdon: Prog. Mater. Sci. Vol. 53 (2008), p. 893.

[5] K. Edalati, T. Fujioka and Z. Horita: Mater. Trans. Vol. 50 (2009), p. 44.

[6] S.W. Lee, K. Edalati and Z. Horita: Mater. Trans. Vol. 51 (2010), p. 1072.

[7] Y. Harai, Y. Ito and Z. Horita: Scripta Mater. Vol. 58 (2008), p. 469.

[8] K. Edalati, Y. Ito, K. Suehiro and Z. Horita: Int. J. Mater. Res. Vol. 100 (2009), p. 1668.

[9] M. Kawasaki, B. Ahn and T.G. Langdon: J. Mater. Sci. Vol. 45 (2010), p. 4583.

[10] C. Xu, Z. Horita, T.G. Langdon, Acta Mater. 55 (2007), p. 203.

[11] K. Edalati, T. Fujioka and Z. Horita: Mater. Sci. Eng. A Vol. 497 (2008), p. 168.

[12] K. Edalati and Z. Horita: Mater. Trans. Vol. 51 (2010), p. 1051.

[13] K. Edalati, E. Matsubara and Z. Horita: Metall. Mater. Trans. A Vol. 40 (2009), p. 2079.

[14] K. Edalati, Z. Horita, S. Yagi and E. Matsubara: Mater. Sci. Eng. A Vol. 523 (2009), p. 277.

[15] K. Edalati, Z. Horita and Y. Mine: Mater. Sci. Eng. A Vol. 527 (2010), p. 2136.

[16] F. Wetscher, A. Vorhauer and R. Pippan: Mater. Sci. Eng. A Vol. 410-411 (2005), p. 213.

[17] K. Edalati and Z. Horita: Scripta Mater. (1991), in press.

[18] A. Buch: Short Handbook of Metal Elements Properties and Elastic Properties of Pure Metals, Krzysztof Biesaga, Warasaw (2005).

[19] H.J. Frost and M. F. Ashby: Deformation-mechanism maps, The plasticity and Creep of metals and ceramics, Pergamon Press, Oxford (1982).

[20] T. Suzuki, Y. Kamimura and H.O.K. Kirchner: Philos. Mag. A Vol. 79 (1999), p. 1629. 